\title{
Assessment of Open Defecation and Prevalence of Soil Transmitted Helminthes among a Tertiary Institution Students in Nigeria
}

\author{
Olufunmilola O. Ajayi and Kyola L. Philip
}

\begin{abstract}
Department of Biological Sciences, Joseph Ayo Babalola University, P. M. B 5006, Ikeji-Arakeji, Osun State, Nigeria. E-Mail Id: ooajayi@jabu.edu.ng
\end{abstract}

\begin{abstract}
Open defecation is a state of passing the indigestible food from the gastrointestinal tract to the open space. This mostly results in the spread of pathogenic microorganisms to susceptible person with majority of the symptoms being diarrhea especially when the infection is caused by intestinal parasite. The illiterates are most times implicated as group of people defecating openly together with lack of toilet facilities. This study was designed to examine open defecation habit among literate and its cause. The study was conducted among the students of a Nigerian University. The hostel premises was surveyed for feaces. A hundred and eight Fresh feaces samples found around the hostel premises were examined microscopically using formol ether concentration technique for presence of soil helminthes. The hostel premises surveyed showed opened defecation on going among the students. Twelve (12\%) percent of the stool examined were positive for soil helminthes (Ascaris lumbricoides and hookworm). The soil helminthes infection was not gender associated $(P>0.05)$ at 95\% confidence interval (CI). Nine point one (9.1\%) of male had mixed infection while $3.0 \%$ had mixed infection among the female. The use of anti-helminthes was statistically significant $(P<0.05)$, being more predominant among the female students. The contributing factors to open defecation among the students were; inadequate water supply, insufficient toilet facility, dirtiness of the toilets especially when cleaners are not around and fear of vaginal infections. University management need to ensure frequent flow of water in the hostels, a toilet may be attached to each room to create sense of belonging among the students which will ensure proper cleaning of the toilets. Likewise lectures on the implication of open defecation on health should be conducted periodically for the students.
\end{abstract}

Keywords-Open defecation, Students, Soil helminthes.

\section{INTRODUCTION}

The world Health Organization estimated about 946 million people in the world defecate in the open such as street gutters, behind bush or open bodies of water (UNICEF, WHO, 2015). In Nigeria the prevalence of open defecation is estimated at 46 million people (FMWR, 2018). This attitude by people have a lot of adverse effect on the health of people in the community where open defecation is practiced. It enhances transmission of disease such as cholera, diarrhea, hepatitis A, typhoid and polio (WHO, 2018). Estimated 280,000 diarrhea deaths occurs annually form infection with pathogenic organism including intestinal worms, schistosomiasis and trachoma as a result of inadequate sanitation (WHO, 2018).

Open defecation mostly occur where there is a large population with few or no access to toilet facility. In order to curb the menace of open defecation, activists and government embarked on building toilet facilities in the communities. However, social norms and attitudes (Routray, 2015) together with inadequate or no water supply stopped people from using them. Ahmad(2014) opined that provision of community toilet should be less focused but shifted on collective behavioral change by people as $1 \%$ defecating in the open puts the health of everybody at risk.

The adverse impact of open defecation can be judged from the fact that one gram of faeces of a person can contain $10,000,000$ viruses, 1,000,000 bacteria, 1,000 parasite cyst and 100 parasite eggs and pathogens. If left in the open, these are carried by flies, fluid (water), finger and field and infect another person through the faecal-oral route. Hookworm, that enters the body through unprotected feet, has a direct link with open defecation. The adverse effect is much in children as the infection cause malnourishing malnutrition, growth stunting, intellectual retardation, and cognitive and educational deficit (UNICEF, 2013; Routray, 2015). 
One of the effect of open defecation is excessive spending on drugs for infection treatments (Ahmad, 2014). There are also strong gender impacts of open defecation. Lack of safe and private toilets exposes women and girls to the dangers of physical attacks and encounters such as snake bites and it is an impediment to girls' education (by being victims of rape)( Jadhavet al., 2016).

Numerous surveys on prevalence of intestinal worms among different groups of people in Nigeria blamed the prevalence and intensity on low level of sanitation, domestic hygiene, poverty and illiteracy. Likewise, open defecation is also associated mainly to poverty and illiteracy. This geared this study to examine possible act of open defecation among literate and the possible factors for open defecation among this group of people. Also the study was designed to determine the presence of intestinal helminthes among the literate people. Tertiary institution was chosen for the study because a level of decency and hygiene was expected among the students because of the training they are undergoing in citadel of knowledge.

\section{MATERIALS AND METHOD}

\subsection{Study Area}

This study was conducted at Joseph Ayo Babalola University (JABU), a first entrepreneurial private Nigerian University located in Ikeji Arakeji. Ikeji-Arakeji is a town in Oriade Local Government Area of Osun state, Nigeria. It is located in western part of Nigeria, $37 \mathrm{~km}$ (20mins drive) from Akure (capital of Ondo state). It lies on latitude $7.4^{\circ} \mathrm{N}$ of the equator and Longitude $4.9^{\circ} \mathrm{E}$. All the students are hostel resident with a population size of 3,000.

\subsection{Sample Selection}

The student hostels premises were chosenfor stool sample collection and fresh stool samples defaecated in the open were collected and examined for soil transmitted helminthes (STH). One hundred and eight (108) samples were collected for the study.

\subsection{Sample Collection}

\subsubsection{Questionnaires}

Structured Questionnaire developed in English language was distributed to 108 consented students and completed. It was administered to obtain information such as gender, age, knowledge and perception of the participants about parasitic infections, use of anti-helminthes, water storage facilities, place and facilities for defaecation.

\subsubsection{Collection of stool specimen}

Samples of faeces were taken into a clean labeled sample bottle with plastic spoon from all the hostels premises. A spoon each was used to pick each sample to prevent cross contamination of the samples. The samples were taken to the Microbiology laboratory of the school were they were analyzed.

\subsubsection{Laboratory Procedure}

The stool was examined using Formol Ether Concentration Technique. For each stool sample, $4 \mathrm{ml}$ of $10 \%$ formalin was dispensed into a test tube. Using an applicator stick, $1 \mathrm{~g}$ of faeces was added to the $4 \mathrm{ml}$ of $10 \%$ formalin. The stool sample was emulsified in the formalin and $3 \mathrm{ml}$ of the same $10 \%$ formalin added to the preparation and shook so as to homogenize the solution. The emulsified faecal sample was sieved into centrifuge bottle using a surgical gauze and funnel.

Three milliliter (3ml) ethyl acetate was added to the suspension, it was then mixed and centrifuged immediately at $1500 \mathrm{rpm}$ for 1minutes. The layer of faecal debris was loosened from side to side of the test tube with the aid of an applicator stick by inverting the test tube so as discard the supernatant. After which the bottom of the tube was tapped to suspend the sediment, a drop of sediment was placed on a clean grease free glass slide. Then a drop of Lugol's iodine was addedto the sample on the slide. Cover slip was used to cover the sediment on the slide carefully avoiding air bubble. It was then examined microscopically using the $\mathrm{x} 10$ and $\mathrm{x} 40$ objective lens with the condenser iris closed sufficiently to give good contrast (WHO, 1991).

\subsection{Statistical Analysis}

The data were entered into Microsoft Excel 2013. Chisquare test was done to find the significant difference in the variables.

\section{RESULTS}

From the study, it was observed that the students practice open defecation. Stool samples were found in the open both in the male and female hostels. Some students defecated behind the hostel windows, hostel premise, while some faeces were thrown over the fence(Plate 1).

One hundred (100) stool samples from the faeces found around the hostel premises were examined for the presence of soil transmitted helminthes. Sixty-seven (77\%) percent of the sample was from female hostel while $33 \%$ was from male hostel. Twelve percent (12\%) of the total samples were infected with soil helminthes (Ascaris and hookworm). Fifty-eight point three percent (58.3\%) of the infected faecal samples had Ascaris lumbricoides egg and $83.3 \%$ had hookworm egg. Forty-one point six $(41.6 \%)$ of the infected samples had mixed infection with Ascaris and hookworm (Figure 1).

Figure 2 shows the distribution of A. lumbricoides and hookworm infection among the gender in the study population. The Ascaris infection was $12.1 \%$ and $4.5 \%$ 
among the male and female students respectively. Hookworm infection was $15.2 \%$ and $7.5 \%$ among male and female students respectively. Three $(9.1 \%)$ had mixed infection among the male while $2(3.0 \%)$ had mixed infection among the female. However, the soil helminthes infection was not gender associated $(\mathrm{P}>0.05)$ at $95 \%$ confidence interval (CI).
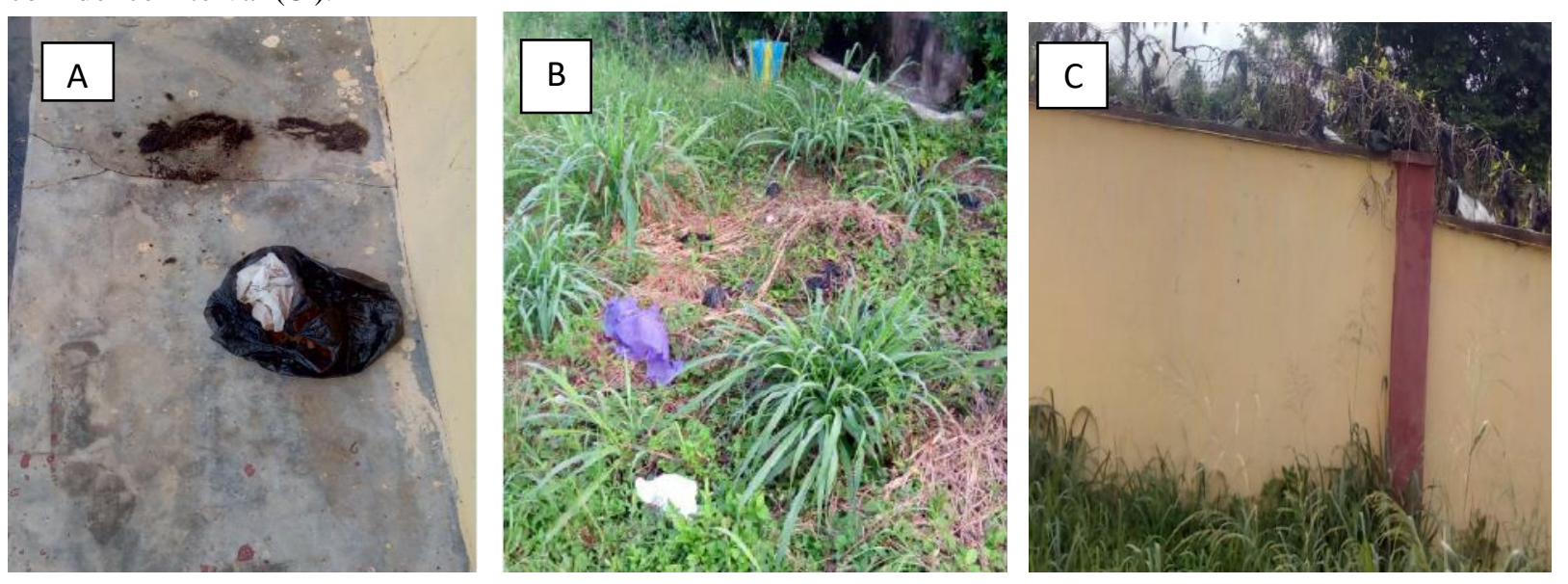

Plate 1: Faecal samples (A) behind hostel hostel window, (B) on bear ground, $(C)$ on hostel fence

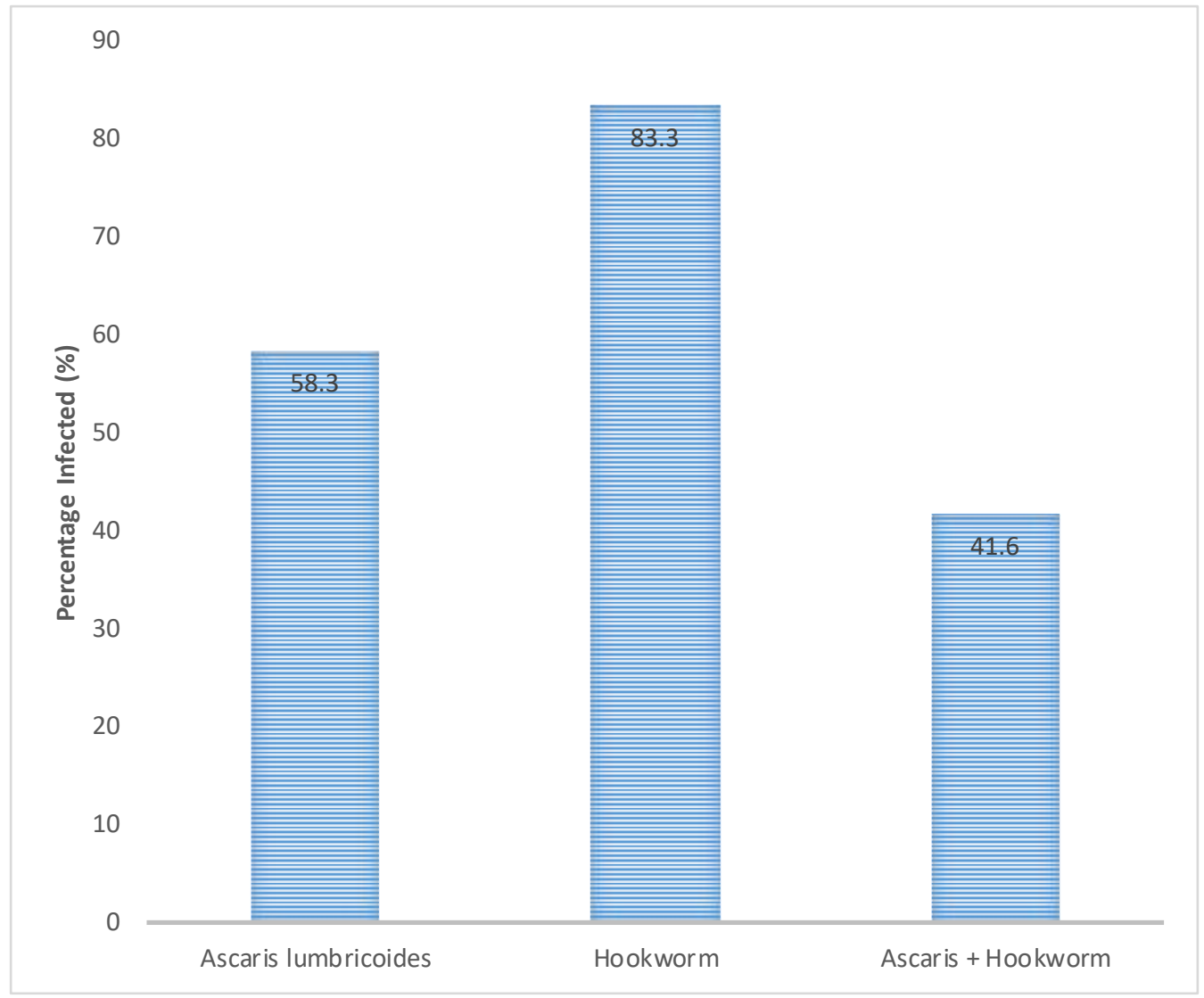

Fig.1: Soil transmitted helminthes found in stool samples.

\section{confidence interval (CI).}

Table 1 shows the use of anti-helminthes by the students. Sixty-two point five percent $(62.5 \%)$ male used antihelminthes while $79.5 \%$ of the female used anti-helminthes. A statistical difference $(\mathrm{P}<0.05)$ was observed among the students based on the use of anti-helminthes. . 


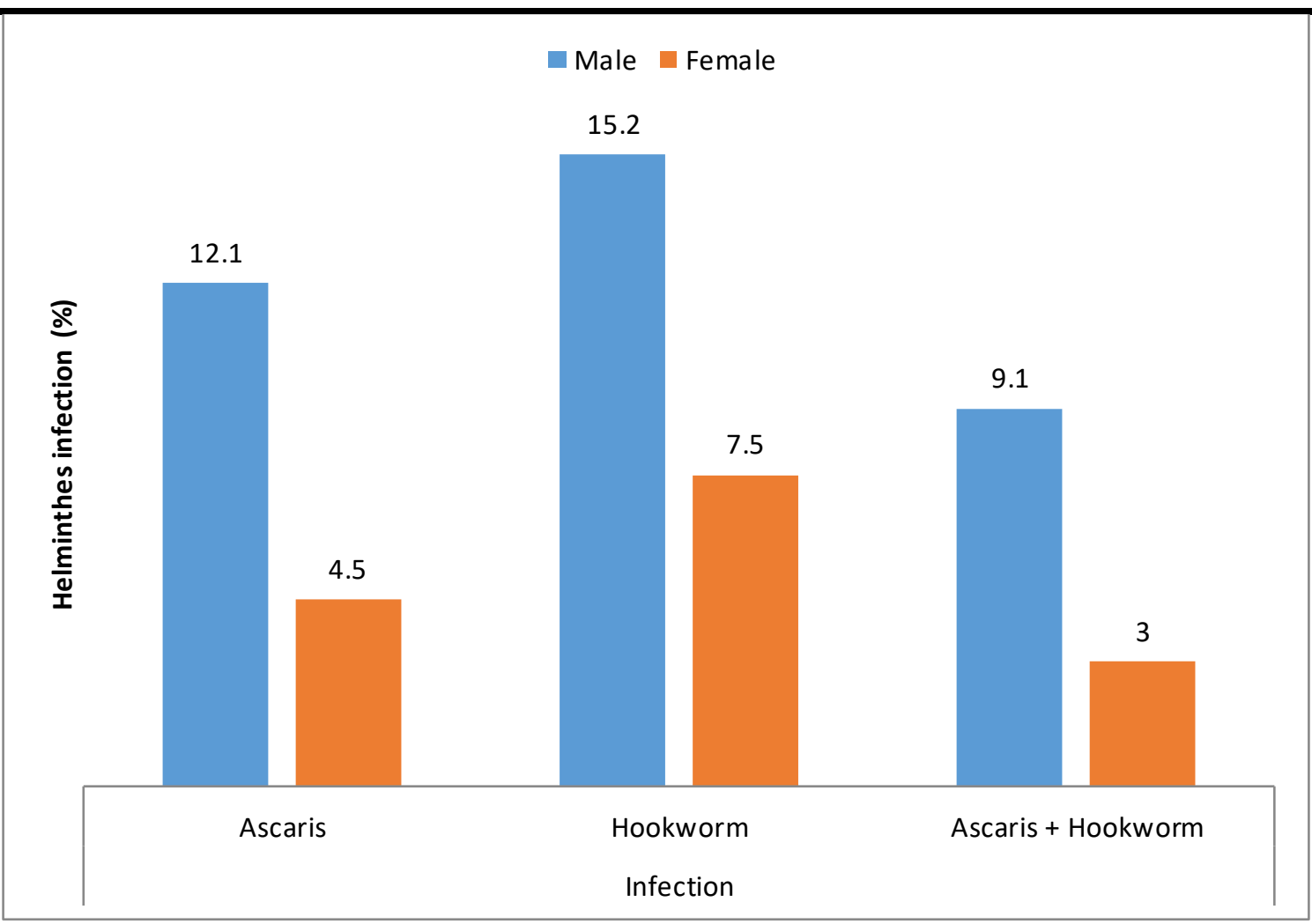

Fig.2: Gender distribution of soil transmitted helminth among students.

Table.1: Gender distribution of anti-helminthes usage by the students

\begin{tabular}{cccc}
\hline & No. of Respondents & $\begin{array}{c}\text { Used Anti-helminthes } \\
\text { No. }(\%)\end{array}$ & $\begin{array}{c}\text { Do not Use Anti- } \\
\text { helminthes } \\
\text { No. }(\%)\end{array}$ \\
\hline Male & 24 & $15(62.5)$ & $9(37.5)$ \\
Female & 83 & $66(79.5)$ & $17(20.5)$ \\
Total & 107 & $81(75.7)$ & $26(24.3)$ \\
\hline
\end{tabular}

Among male students, 20.4\% defecatedin toilet, 0\% used potty, and $1.9 \%$ open defecatedin space. Among female students $40.7 \%$ used toilet, $30.6 \%$ used potty, and $6.5 \%$ used open space (Figure 3). There was a significant difference $(\mathrm{P}<0.05)$ between male and female based on facilities used by the students for defecation.

Most of the fresh stool samples used for the study were collected during the weekends. Each block of the hostel comprises of 24 rooms with 16 toilets. There are four students in a room. There are 96 students per block with 16 toilets. Therefore, the ratio of student to toilet provided by the school is $6: 1$.
From the questionnaire interview, information obtained was that water supplied to the hostel stayed mostly for 5 hours in a day (Figure 4). Twelve point five percent (12.5\%) and $44.4 \%$ of male and females respectively are in habit of storing water in personal storage facilities (Table 2). A statistical significant difference $(\mathrm{P}<0.05)$ is obtained in water storage habit among the two genders. The toilets are washed by the cleaners and they only worked during the week days. From the study population it was observed that the male students have higher helminthes infection than the female students. 


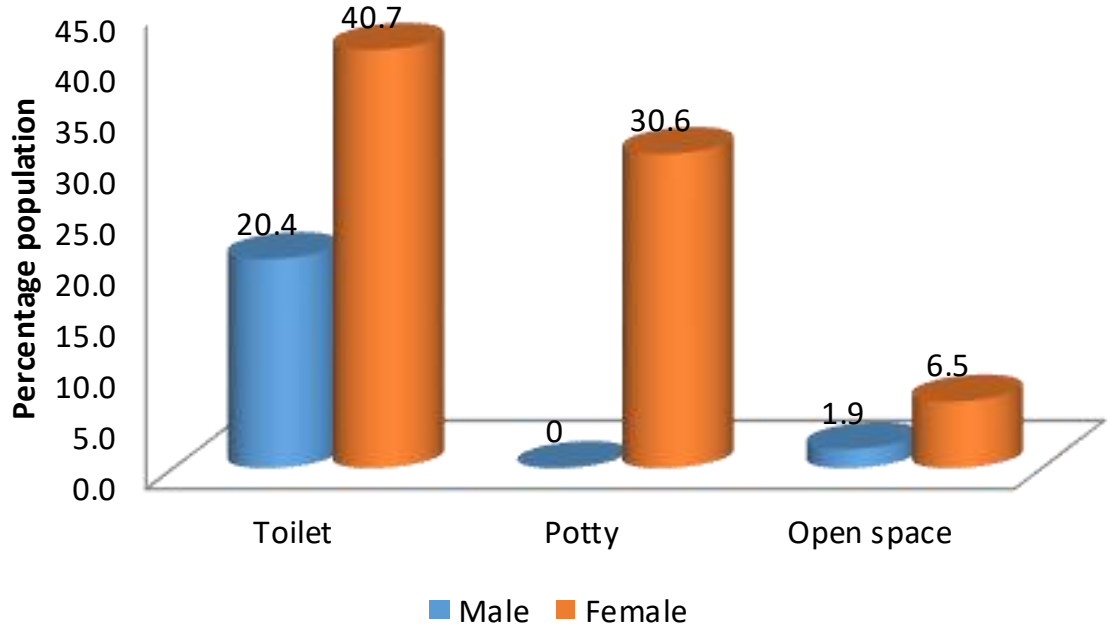

Fig.3: Facilities used for defecation by the students

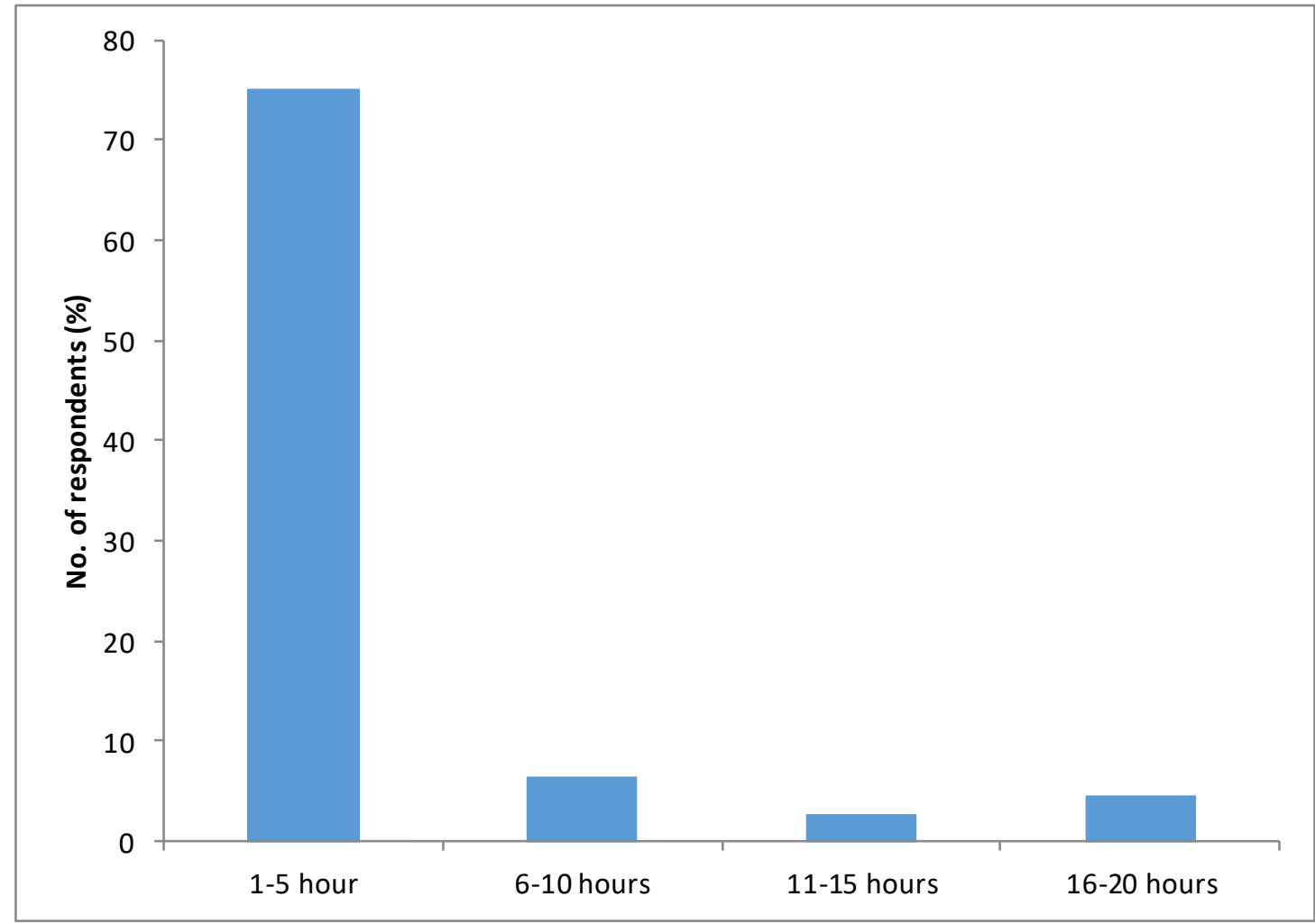

Fig.4: Hours of water supply in the hostel

Table.2: Water storage habit among the students in the hostel

\begin{tabular}{cccc}
\hline Gender & Total no. of respondent & Stores water No. & $\begin{array}{c}\text { Do not store water } \\
\text { No. }(\%)\end{array}$ \\
\hline Male & 24 & $3(12.5)$ & $21(87.5)$ \\
Female & 81 & $36(44.4)$ & $45(55.6)$ \\
Total & 105 & $39(37.1)$ & $66(62.9)$ \\
\hline
\end{tabular}




\section{DISSCUSION}

Open defecation has been a major problem in developing country. Some of the reasons were due to unavailability of toilet facilities in houses especially in the rural areas and lack of public toilets in most human communities. The result from this study help to elucidate that open defecation is not limited to unlearned population and may not probably due to lack of toilet facility as also observed by Routray et al (2015). A level of decency is expected among the students of higher institution because of their training to become literate and respected people in the community. In contrast, the study population in this study reacted negatively to the expectation.

Stool sample was found littering the hostel environment where the students reside. Some of the factors of open defecation found from this study were insufficient toilet facility provided for the students, inadequate water supply to the hostel and unavailability of cleaners during the weekend to clean the toilets because majority of stool samples got for the study was during the weekends. This implies that common toilets may face the problem of cleaning due to lack of who takes responsibility of cleaning the toilets. It had been noticed that most people are in habit of not flushing the toilet even when there is water in the cistern. So most time the dirtiness of toilets which pushed some people to defecate in the open air is as a result of human behavior towards hygienic usage of the toilets. The finding corroborate the opinion of Ahmad (2014) that the focus on making a community open defecation free should be more on human behavior and not majorly on building community toilet facilities.

It was observed from the study that higher number of female students have facilities for storing water more than the male students. Nevertheless, open defecation was higher among the females than the males. The major reason given by the students that practice open defecation was avoidance of vaginal infection which may be contracted from the use of dirty toilets. The splash of water which might have been used by infected person to the vaginal may result in infection with some microorganisms such as yeast and Bacteria. A study conducted by Ojo and Anibijuwon (2010) among the female students of University of Ado Ekiti in Nigeria linked urinary tract infection to state of toilet facility.

The soil-transmitted helminthes found from the stool samples were Ascaris lumbricoides and hookworm. The prevalence of soil helminthes found in this study was lower than the prevalence obtained by Oyeniran et al. (2014) and Olaniran et al. (2015) among school children both in Osun state. The lower prevalence observed in this study may be due the possibility of getting the sample from few infected persons since the sample were gotten indirectly. The male students have higher helminthes infection than the female. This may be due to low usage of anti-helminths among the male students and also theirhabit of removing foot wear when playing football. Since the hostel premises are littered with faeces because of open defecation, there is a great tendency of helminth larvae present in the soil. This explains the reason for high hookworm infection among the male students in this study.

In conclusion, the level of education does not correlate to behavioural pattern among people. Likewise, to subvertthe habit of open defecation among students of higher learning, adequate provision of toilet facilities with regular water supply is needed. Possibly the hostel room should be designed in such a manner that each room will have a toilet attached to it. Self-contained room system may be adopted by the universities to help in preventing open defecation among the students. Also campaign against open defecation should not be limited to the rural communities alone but should be extended to schools. The students need to be lectured on the adverse effects of open defecation such as transmission of pathogenic organisms which can affect their well-being.

\section{ACKNOWLEDGEMENT}

We appreciate the management of Joseph Ayo Babalola University for creating an enabling environment for the conduct of this research work. All the staff of the Department of Biological Sciences are also appreciated for their support during the period of the research. To the students who participated in the research, we say thank you.

\section{REFERENCES}

[1] Ahmad Junaid, (2014). How to Eliminate Open Defecaion by 2030. https://www.devex.com/news/how-to-eliminate-opendefecation-by-2030-84634

[2] Federal Ministry of Water Resources (2018). Making Nigeria open-defecation-free by 2025; A National Road Map. Page 1-72.

[3] Jadhav, A., Weitzman, A. and Smith-Greenaway, E. (2016). Household sanitation facilities and women's risk of non-partner sexual violence in India. $B M C$ Public Health. 16:1139

[4] Ojo, O. O. and Anibijuwon, I. B. (2010). Urinary tract infection among female students residing in the campus of the University of Ado Ekiti, Nigeria. 
African Journal of Microbiology Research. 4(12):

1195-1198

[5] Olaniran, O., Ajayi, O. O., Odetoyinbo, B. W., Afolayan, D. O., Awoyeni E. A., Adekunle, O. T. and Oyetoke, O. O. (2015). Prevalence of soil transmitted helminthes among school children in central Local Government Area Ile-Ife, Osun State, Nigeria. International Journal of Novel Research in Interdisciplinary Studies 2(2):8-13.

[6] Oyeniran O.A., Ojurongbe O., Oladipo E.K., Afolabi A.Y., Ajayi O.O and Oloke A.A (2014). Journal of Dental and Medical Sciences. Vol. 13(7): pp 96-101

[7] Routray, P., Schmidt, W., Boisson, S., Clasen, T. and Marion W. Jenkins, M. W. (2015). Socio-cultural and behavioural factors constraining latrine adoption in rural coastal Odisha: an exploratory qualitative study. BMC Public Health (2015) 15:880

[8] UNICEF (2013). Sanitation Factsheet for World Toilet Day 2013.

https://www.unicef.org/toilets4all/WTD Sanitation F actsheet November 2013.pdf

[9] UNICEF/WHO (2015). 25 years progress on sanitation and drinking water: 2015 update and MDG as ses sment, WHO Press, Geneva, Switzerland.

[10] World Health Organization (1991). Basic laboratory methods in medical parasitology. Geneva: World Health

Organization. http://www.who.int/iris/handle/10665/4 $\underline{0793}$

[11] World Health Organization(2018). Fact sheet on environmental sanitation: Open-air defecation. Accessed online $24^{\text {th }}$ July, 2018. 